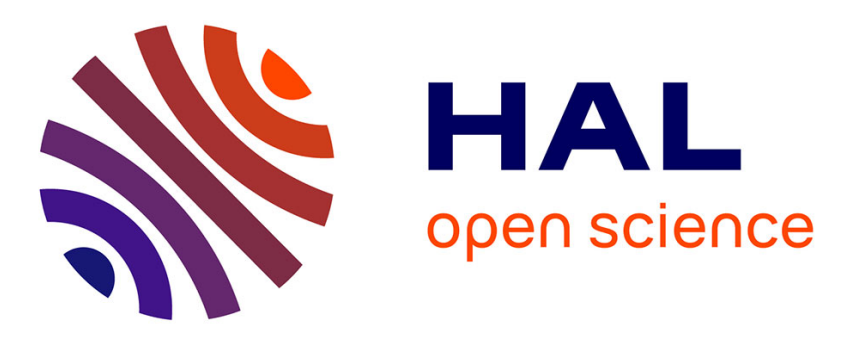

\title{
Electric Power Controller for Steering Wheel Management in Electric Cars
}

Vicente Milanés, Joshué Pérez Rastelli, Enrique Onieva, Carlos González, Teresa de Pedro

\section{- To cite this version:}

Vicente Milanés, Joshué Pérez Rastelli, Enrique Onieva, Carlos González, Teresa de Pedro. Electric Power Controller for Steering Wheel Management in Electric Cars. Compatability and Power Electronics 2009., May 2009, Badajoz, Spain. hal-00738075

\section{HAL Id: hal-00738075 \\ https://hal.inria.fr/hal-00738075}

Submitted on 3 Oct 2012

HAL is a multi-disciplinary open access archive for the deposit and dissemination of scientific research documents, whether they are published or not. The documents may come from teaching and research institutions in France or abroad, or from public or private research centers.
L'archive ouverte pluridisciplinaire HAL, est destinée au dépôt et à la diffusion de documents scientifiques de niveau recherche, publiés ou non, émanant des établissements d'enseignement et de recherche français ou étrangers, des laboratoires publics ou privés. 


\title{
Electric Power Controller for Steering Wheel Management in Electric Cars
}

\author{
Vicente Milanés, Joshué Pérez, Enrique Onieva, Carlos González, Teresa de Pedro \\ Consejo Superior de Investigaciones Científicas -Instituto de Automática Industrial (Madrid, Spain) \\ \{vmilanes, jperez, onieva, gonzalez, tere\}@iai.csic.es
}

\begin{abstract}
- driverless driving is one of the most interesting topics in the field of the intelligent transportation systems. Among these topics, the automation of the actuators involved in the management of a car, and out of them the control of the steering wheel constitute one of the most complex. In this paper, automatic power steering architecture to manage the steering wheel via Ethernet controller is developed. An on-board PC is connected to the controller to permit handling by computer generated signals. An electric car has been equipped with the system designed and tests to prove the behavior of the system in actual situations in the private driving circuit at the IAI facilities are included.
\end{abstract}

Index Terms - Autonomous vehicles, Power control, System analysis and design, Intelligent transportation systems.

\section{INTRODUCTION}

The increase in the number of cars in the last two decades has caused to the governments a lot of worry. Different solutions such as the building of new transport infrastructures or increasing the fines to the drivers in case of inappropriate driving have not achieved the goal of reducing the number of fatalities in highways or the traffic congestion in urban areas.

Intelligent transportation systems (ITS) [1] focus on improving the safety in the roads actuating on two possible aspects. On one hand, the infrastructure and the possibilities to optimize the traffic flow. On the other hand actuating on the cars and the actuators involved in the tasks associated to the driving, that is, steering wheel, brake and throttle.

Nowadays, the idea of driverless car traveling around the cities is a utopia. However, some advances in this way have been achieved in the last years. From the point of view of automobile industry several aids to the driver have been included. Systems to advice about risk situations such as blind angle detection trough infrared cameras or adaptive cruise control through long-range radar sensing technology which tracks information up to 150 metres ahead in all weather and road conditions are being implemented in mass-produced cars.

With respect to the research field, US department of defense organizes the DARPA Urban Challenge [2] whose event required teams to build an autonomous vehicle capable of driving in traffic, performing complex maneuvers such as merging, passing, parking and negotiating intersections. In Europe, we can emphasize the Lara project [3] from INRIA in France focusing on the development and experimentation of techniques for new forms of urban transport and the Argo
Project [4] form University of Parma in Italy whose goal is to develop active safety systems for vehicles of the future.

Guidance of autonomous vehicles is one of the most important research topics in the intelligent transportation systems field. The main actuator involved in this task is the steering wheel whose position in every moment is to be known if a good controller is to be obtained.

The difficulty of manually moving the steering wheel has caused the apparition of two kinds of systems to aid the drivers. If an engine-driven hydraulic system is used to aid the motion of the steering wheel they are named hydraulic power steering (HPS) systems. If an electric motor is used then they are named electric power steering (EPS) systems.

A model of an EPS system is presented in [5] where the inputs are the motor torque, the driver steering torque and the front wheels aligning torque and the output is the steering angle of the front wheels. With respect to HPS system, Ferries [6] models the behavior of the system during low speed steering maneuvers and Gao [7] presents a linear low order model to emulate an HPS system for heavy duty vehicles.

As for as experimental results, Graovac [8] designs a method to choose the optimal PWM method for driving 3-phase inverter in automotive EPS and HPS applications and Rhyu [9] presents a hybrid electro-hydraulic power steering (EHPS) system of $42 \mathrm{~V}$ automobile.

In this paper, the automation of the steering wheel in an electric Citroën Berlingo van is presented. This model, whose production stopped in 2005, is similar to the petrol one. The main characteristic in the steering is the inclusion of an electric motor to supply the power steering hydraulic pump.

A system to commute between automatic and manual driving is installed and a DC motor governed via Ethernet controller is used to know the position of the steering wheel with the feedback of an encoder. A laptop, in which the control software is installed, is connected to the Ethernet controller. A test-bench to show the behavior of the system designed are included and a comparison among the stretch straights and curve straights with right and left turns is proved. Once the system is installed and tested the incorporation to the fuzzy logic based AUTOPIA control architecture is carried out and a final demonstration of the automatic steering wheel control while driving in a real road is done.

In the follow sections we describe the system designed, its assembly and implementation in an electric Citroën Berlingo 
van. Different experiments to show the behavior in real situations are included. Finally, the adaptation of the system to the AUTOPIA control architecture is carried out.

\section{Automation OF THE SteERING WheEL}

\section{A. Design of the autonomous system}

The decision to implement and automatic steering wheel system was taken conditioned to keeping the original steering wheel system of our electric car. For this reason the decision taken was to put a gear pulled by a lever to select between the two systems. Through this lever we can commute between both steering systems easily using the standard car system that permits to regulate manually the position of the steering wheel in the low position, or the automatic one controlled by the system designed in the high position.

Before proceeding with de design, the expected requirements of the automatic system were set. The first step in the design of the steering wheel control was to take into account the limitation set by the power supply: All the energy is to come from the 12-volts vehicle's battery.

When the alternative system is selected, a, 12-volt DC motor to automatically move the steering wheel is needed. The system is organized as a DC motor attached to the direction bar through two gears, one in the motor rotor and other in the axe. The motor can be controlled in different ways. In our case, a PID discrete controller is used. The control loop is closed by an incremental 500 pulse per turn encoder. The system described is shown in fig 1 .

One of the goals in AUTOPIA project is to try to mimic the human behavior in driving situations. Based on this premise, the time needed to turn the steering wheel from the leftmost position to the rightmost one by a driver was determined experimentally. This time ( 8 seconds) was used to calculate the steering wheel turning speed resulting in a value of $22.5 \mathrm{rpm}$.

Other important parameter with influence in the selection of the motor is the torque. The situation when a higher torque is required occurs when the vehicle is stopped and the four

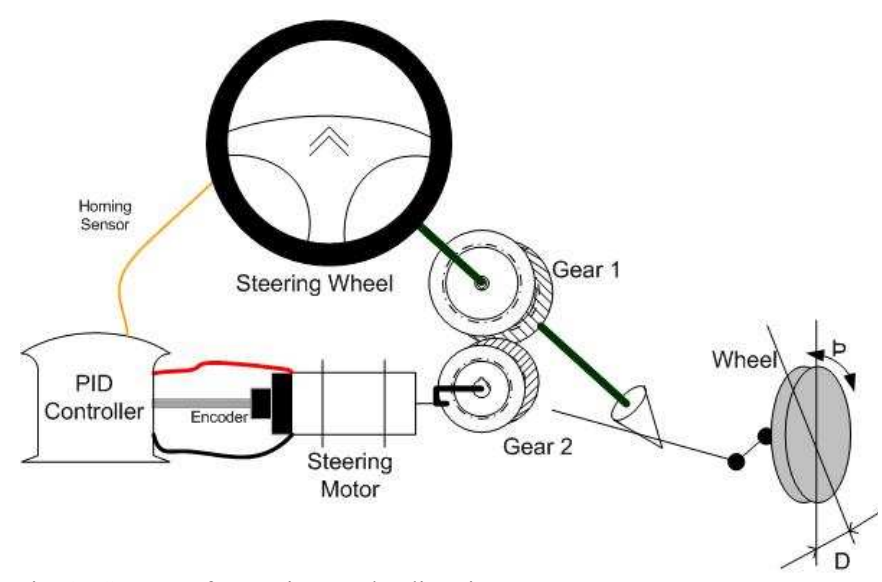

Fig. 1. System of actuation on the direction axes. wheels of the vehicle are in contact with the ground. A torque wrench in the central axe was use to calculate the torque needed to move the steering axe. To this value, $5 \mathrm{Nm}$, a security factor was added to obtain a final angular force of 7 $\mathrm{Nm}$.

The power for the motor is critical because it is fed from the battery of the electric car and the more power is required by the motor the more charge from the battery is demanded. For this reason, the maximum current was fixed up to 8 amperes. The model of the motor is a FaulHaber model 3863012C, with a reduction stage $66: 1$ to permit a reduction in the angular speed of the motor (from $6500 \mathrm{rpm}$ to $98,49 \mathrm{rpm}$ ) and increase the nominal torque (from $110 \mathrm{mNm}$ to $7,26 \mathrm{Nm}$ ).

After designing the automatic steering wheel system, it was necessary to determine how to gear it to the steering bar. A good relation between the gear of the motor and that of the direction bar can be 5:4. But, the availability of the market and dimension of the diameters caused that a relation 4:3 was used, with 120 and 90 teeth respectively. This relationship fixes the final angular speed in 73,86 rpm (greater than 22,5 rpm) and the final torque in 9,67 $\mathrm{Nm}$ (greater than $7 \mathrm{Nm}$ ) fulfilling the conditions of design.

The next step in the design is the choice of the controller. Previously, an older motor steering system had been implemented with a bus ISA card, coupled in the backplane of the main PC, which emulated a discrete PID (based on a LM628), moreover, the power stage was implemented in other custom made card with a typical $\mathrm{H}$ bridge, controlled through a PWM signal, coming from the first mentioned card.

The older controller system had a main problem: the dependence on a backplane PC with ISA cards. This kind of cards are falling into disuse and making the replacement of the computer difficult. Due to this problem, the main prerequisite to choose the power controller was based on the selection of a peripheral controller fully independent of the on-board PC technology. A homing sensor was needed to determine the position of the steering wheel at the initialization.

Currently, the technology used in control of DC motors, permits the use of a power stage with a small size and including an easy communication systems with the main PC controller (via Ethernet, USB or serial port). The new controller used is a motion control with Ethernet connection and with the capacity of controlling a brushless motor through a discrete PID, in addition with the homing sensor. The controller is a Fmod-IPECMOT 48/10 made by FiveCo.

This controller needs a power voltage between 15 and 48 volts. To insure its correct supply, a 12-24 volts DC-DC converter is used to feed it. Fig 2 shows the scheme of the steering wheel controller. In the bottom left part of the figure we see the power supply for the system coming from the lighter plug and connected to the DC-DC converter. The converter feeds the power controller and it has three inputs: one from the laptop executing the fuzzy controller that commands it; another from the homing sensor and the last one 


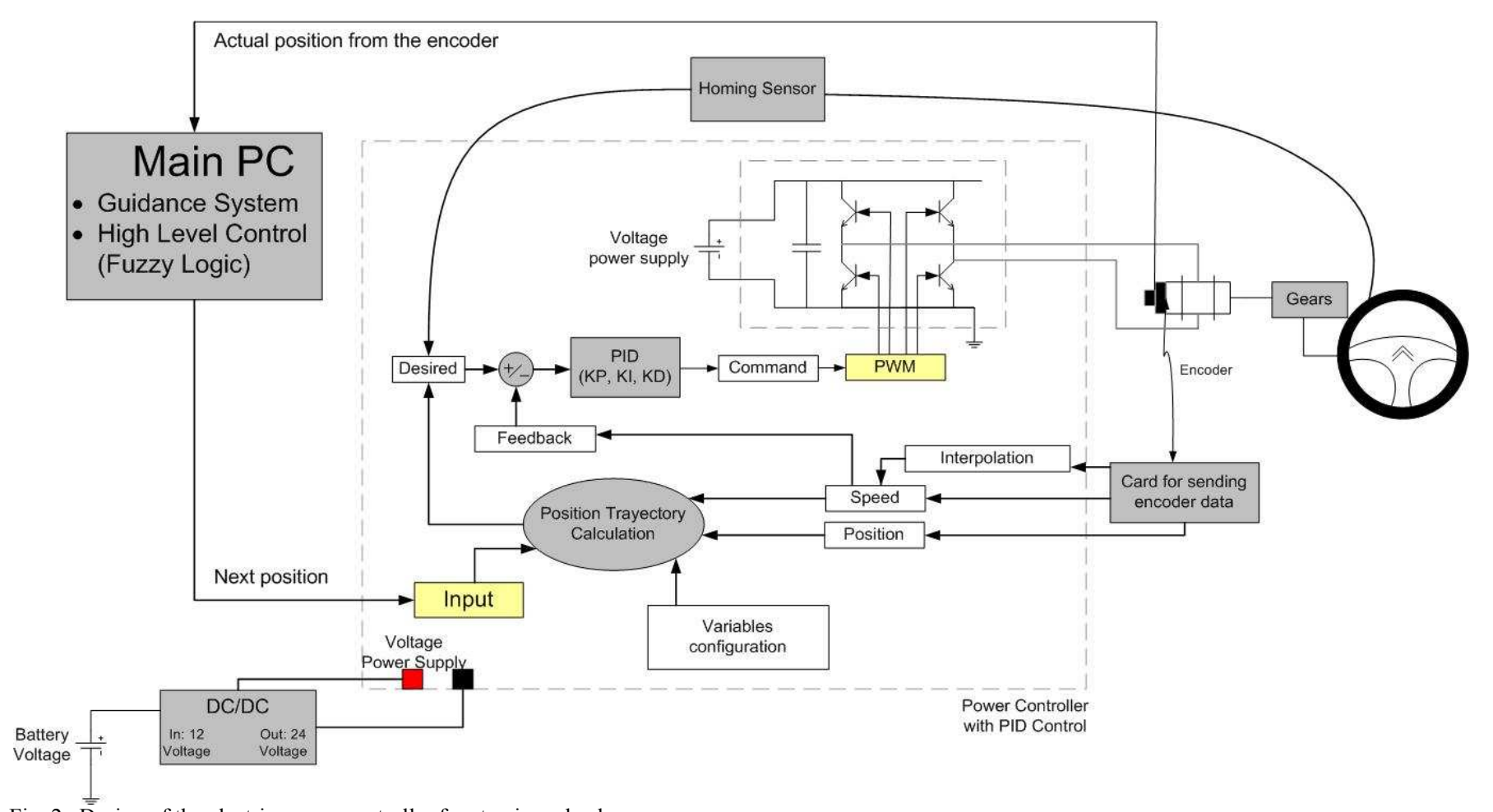

Fig. 2. $\overline{\bar{D}}$ esign of the electric power controller for steering wheel.

from the 12-volts DC motor encoder used to know, after the initialization, the position of the steering wheel.

The next position reference value comes from the laptop and is the new target for the PID controller which, through a PWM governed H-bridge drives the DC motor.

\section{B. Assembly in Rocinante}

Once the control system for the steering wheel is designed, the next step is its location and assembly in the electric car. Thanks to the size of the motor, it is possible to place it close to the gear that moves the automatic system.

The power for the motor is supplied by the power controller that is fixed near to the automatic gearbox and, in the same

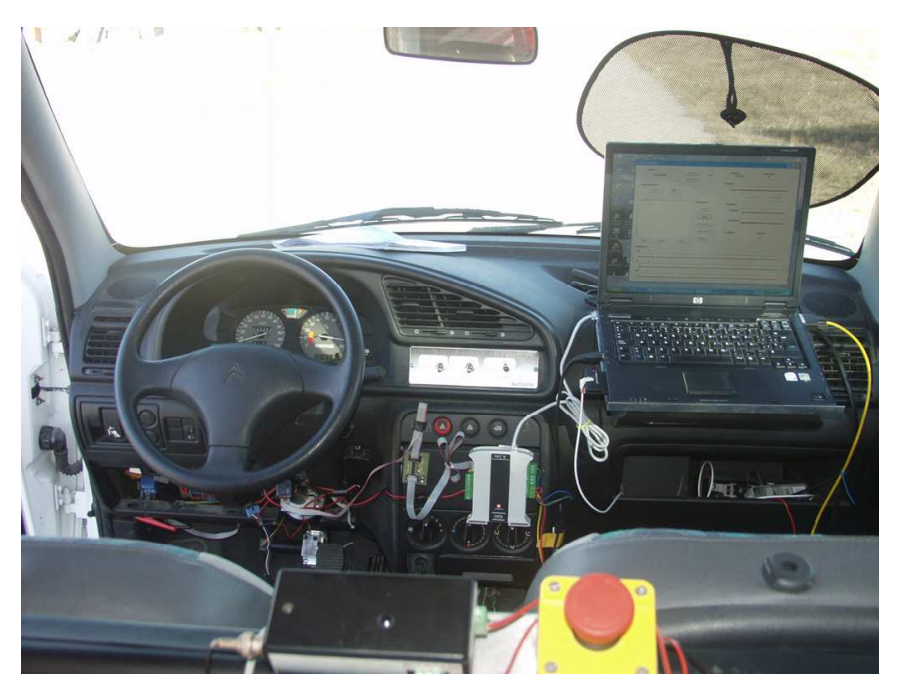

Fig. 3. Assembly of the designed system in Rocinante. location, the DC-DC converter. This converter is connected to the electric car's lighter to supply energy for the system.

Finally, an Ethernet cable to connect the power controller with the laptop that is located in front of the copilot seat is putted. Fig. 3 show the location of all the components in the electric Citroën Berlingo van.

\section{PID Controller Adjust}

The control system used in the steering wheel is a classical cascade control, with two feedback loops. The primary or main loop is controlled by a fuzzy logic system in the central PC. This loop is closed by the GPS, which is used to calculate the angular error (in degrees) and the deviation (in meters) respect to the predefined trajectory. As we said earlier, the inner or secondary loop used a PID controller and is closed with the incremental encoder.

It is important to make a good estimation of the PID parameters. The first step is to identify the system. In order to do this we coupled the motor to the steering wheel, after we set the system in open loop i.e. without feedback, and with a pulse of excitation from an external source. For this test we located the steering as much to the right as possible. Since it can make three full turns, it means this position is located 540 degrees to the right of the center. We then sample the response of the system to the pulse.

With the data taken, and using the ident tool of Matlab, the second order Transfer function was identified and is shown in (1).

$$
H(s)=\frac{0.8866 * e^{-0.5}}{(S+3.9609)(S+4.005)}
$$




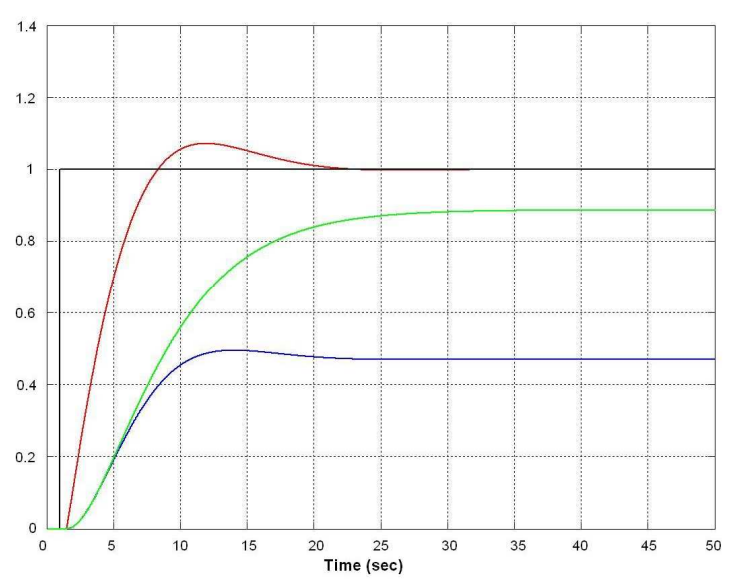

Fig. 4. Step response of the PID controller designed.

Finally, using the Ziegler Nichols adjust, we obtain the PID gains (KP: 2.6003, KI: 0.4333 and KD: 3.90045). These values correspond to a non interactive PID which is adapted to the sampling frequency.

The frequency in the secondary loop is faster than in the primary, by a factor of 10 . The GPS sends the data at a $5 \mathrm{~Hz}$ rate $(200 \mathrm{~ms})$, and the PID controller receives the data from the encoder to $50 \mathrm{~Hz}$ rate $(20 \mathrm{~ms})$.

Fig 4 shows the simulation results of the system designed for a step input represented in the figure for the black line. The green line indicates the response of the system in open loop, the blue one show the behavior in close loop without PID controller and the red one presents the response with the estimated PID controller in (1). We can see as, in open loop, the system is not capable to reach the steady-state due to the absence of feedback and without controller the response is not capable to reach the reference. The system with the PID controller presents an overshoot that is adjusted manually in the experimental tests.

\section{TEST-BENCH IN LABORATORY}

Before mounting the system designed in the electric car,

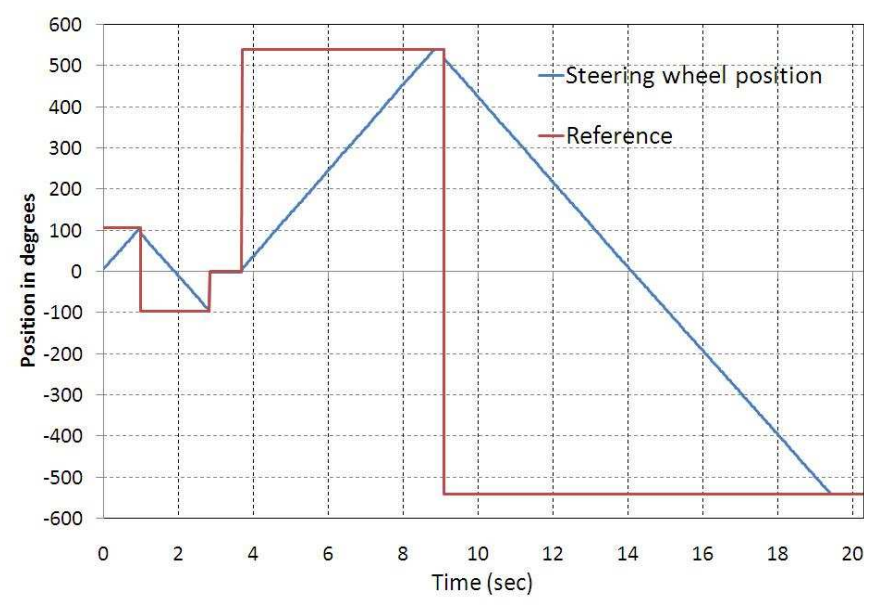

Fig. 5. Test-bench laboratory results. different tests to prove the behavior of the system were carried out. The goal was to obtain the system response while performing curves to the right and to the left. To this end, the target turning speed of the controller was fixed at its maximum value and different references for the steering wheel position were consigned.

The test shown in fig. 5 was developed to take into account two possible situations. The first part of the test consists in a 100 degrees turn to the right and 200 degrees to the left and the goal is to emulate the driver reaction in case of a pronounced bend in a realistic driving situation.

The second part of the test shows another typical situation in driving: the movement of the steering wheel in a traffic circle. In this case, the movement demanded to the steering wheel is a full turning of it. In the first part is 540 degrees to the right and then three full turns to the left.

In both cases, the blue line represents the actual position vs. time while the red line indicates the target reference in each moment. The behavior of the system is perfectly linear as it can be seen.

\section{EXPERIMENTAL RESULTS WITH AUTOPIA CONTROL ARCHITECTURE}

\section{A. AUTOPIA group}

AUTOPIA is a research group with more than 10 years of experience in the design, development and implantation of control systems for the guidance of autonomous vehicles. This experience derives from more than 30 years working in autonomous robots and the adaptation of this knowledgement to vehicles. With the premise of avoiding significant modifications to the original systems of the vehicles, automatic systems has been developed and experiments have been made to confirm the designs and good results have been achieved.

To this end, a private driving circuit has been constructed in the IAI facilities, which represents an inner city area. It is formed by four blocks where one of them finishes in a traffic circle. Thanks to this circuit, real situations in urban areas can

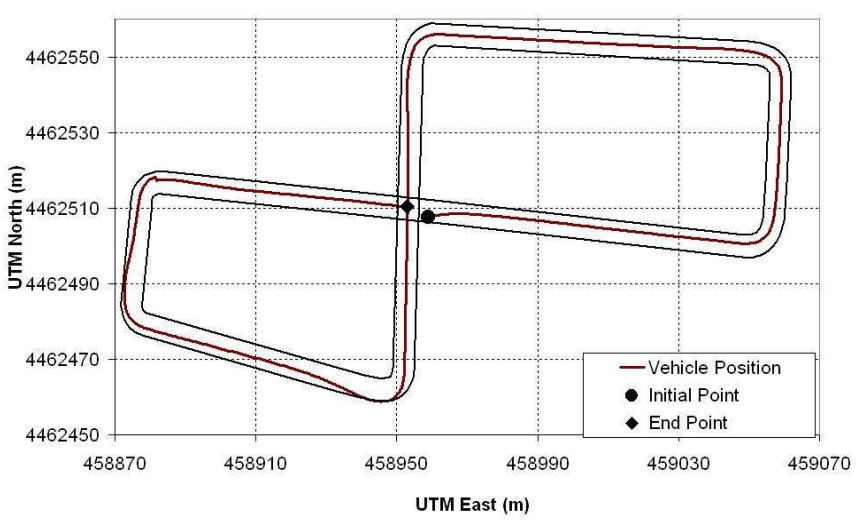

Fig. 6. Route followed by the vehicle. 


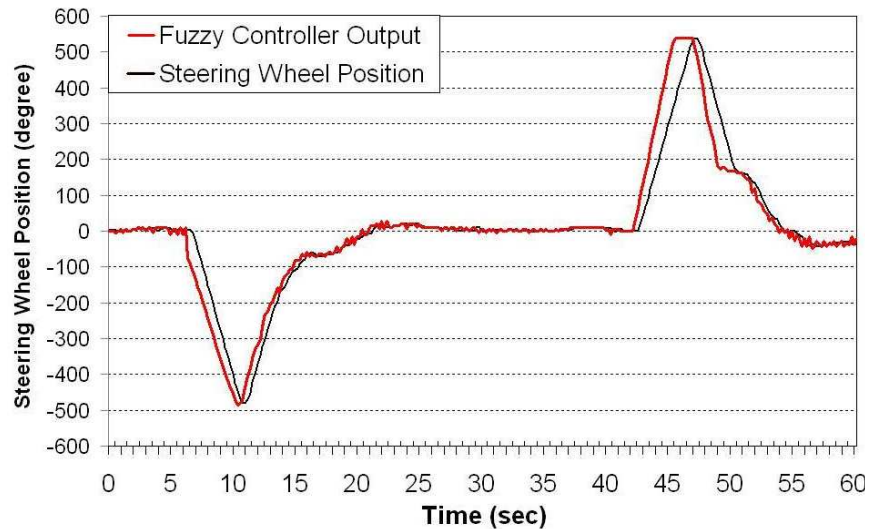

Fig. 7. Experimental results of the output of the fuzzy controller and the PID controller.

be simulated easily allowing testing the autonomous vehicles in a safety environment.

Each car is equipped with a Real Time Kinematic Differential Global Positioning System (RTK-DGPS) that is taken care of realizing the guidance of the vehicles. This positioning system is capable of obtain a maximum error with respect to the position of a fixed base station under 2 centimeters. So, we can know in a global coordinate system the position of each car with great accuracy.

The communication between the base station and each car as well as among cars is carried out through a wireless LAN. All this equipment is governed by an on-board PC that realizes the control of the vehicles through fuzzy logic rules.

The AUTOPIA fleet is formed by two Citroën Berlingo vans and a Citroën C3 Pluriel that are fully automated and a Citroën C3 that is equipped with a DGPS and a wireless LAN but is managed manually. The automation of the two Berlingo vans was based on an ISA power controller. Nowadays, the utilization of this kind of bus is falling into disuse and the actualization of the controller is mandatory. A peripheral controller to make it independent of the on-board PC allows replacing the hardware components of the AUTOPIA architecture easily.

\section{B. Experimental results}

Managing the steering wheel of a car can be a very complex task, since it can depend on a large set of variables and circumstances, some of them can be measured or prevented, such as the deviation from the lane, current speed, etc; but most of them are unpredictable or very difficult to measure, such as wheels' pressure or road's irregularities. These kinds of irregularities can affect in the way that the steering wheel has to be managed with high error tolerance.

In the other hand it cannot be forgotten the accuracy and time response of the system, because sometimes it can be vital if the system is managing a vehicle with persons inside.

The compromise between accuracy, complexity, and time is the main factor on design of this kind of systems. A well proved way to solve this kind of problems is the use of artificial intelligence techniques. These methods are specially indicated when we try to emulate human control actions, such as human car driving. Particularly, fuzzy logic is a well known methodology for these tasks [10] since Sugeno's works [11] about vehicle control in early 1990's.

In this work, during the experiments a fuzzy controller has fed the PID controller with the desired reference positions for the steering wheel and the appropriate turn speed to reach it in order to test the accuracy of the PID controller on real driving situations [12].

The route tracked by the vehicle is shown in fig. 6. During the route, the fuzzy controller sends information about the desired steering wheel position to the PID controller. This has been done attempting to reach the desired position with the maximum speed. The goal during this experiment was to follow the center of the road. The route is formed by six bends, the three first to the left and the last ones to the right.

The problem arises in the fourth bend where an angle over 100 degrees forces the car to do a big movement of the steering wheel. The power controller designed is capable of keeping the car in the road and, through the fuzzy logic, getting it back to the center of the road.

Results in the third and fourth curve segments monitored can be seen in fig. 7. The results show the comparison between the output of the fuzzy controller for the steering wheel position and the output of the PID controller that is sent to the DC motor. The PID controller introduces a minimum delay but decisively contributes to stabilize the input of the DC motor.

\section{CONCLUSIONS}

Automatic car driving across the cities is an unreachable target these days, however the advances in this field contribute towards reducing the number of fatalities in the road or, at least, mitigating their consequences. When we consider the automatic cars, the transfer of the steering control to an automatic system is to be considered with care because it can be very risky. In this paper, a steering wheel controller has been developed.

Automatic systems ought to allow the commutation between manual and automatic system. We have developed a system based on the adjustment of two gears through a lever is a good solution to choose between them. Once the automatic is activated, 12-volts DC motor controlled through an encoder by a power electronic controller has been installed. A laptop to introduce the orders to manage the controller via Ethernet is located in the electric car.

An identification of the system and a simulation to estimate the PID controller in order to close the loop control was carried out and a comparison with the system in case of open loop or without PID controller was included.

The tests show the behavior of the designed system. These tests prove the good reaction in conditions of sharp bends both the right and the left. The response shows the system is capable of tracking paths in real driving situations. 
The inclusion of the system in the AUTOPIA control architecture has been carried out. Different experiments to demonstrate the operation of the system in an autonomous way have been included. The results show the structural design that allows including new control system with minor changes.

\section{ACKNOWLEDGMENTS}

This work was carried out with the support of TRANSITO (TRA2008-06602-C03-01) project from Plan Nacional, GUIADE (P 9/08) project from Ministerio de Fomento and MARTA project (CENIT-20072006).

\section{REFERENCES}

[1] L. Qi, "Research on Intelligent Transportation System Technologies and Applications," in Workshop on Power Electronics and Intelligent Transportation System, pp. 529-531, August 2008.

[2] S. Kammel, B. Pitzer, S. Vacek, J. Schroeder, C. Frese, M. Werling and M. Goebl, “Team AnnieWAY Technical System Description,” Technical Report in DARPA Urban Challenge, January 2007.

[3] R. Benenson, S. Petti, T. Fraichard and M. Parent, "Toward Urban driverless vehicles," in International Journal of Vehicle Autonomous Systems, vol. 6, pp. 4-23, 2008

[4] A. Broggi, M. Bertozzi, A. Fascioli, C. Guarino and A. Piazzi, "The ARGO Autonomous Vehicle's Vision and Control Systems," in International Journal of Intelligent Control and Systems, vol. 3, no. 4, 2000.

[5] M. T. Raharijaona, M. G. Duc and M. S. Mammar, "Linear Parametervarying Control and H-infinity synthesis dedicated to Lateral Driving Assistance," in IEEE Intelligent Vehicles Symposium, pp. 407-412, June 2004.

[6] G. R. Ferries and R. L. Arbanas, "Control/Structure Interaction in Hydraulic Power Steering Systems," in Proceedings of the American Control Conference, pp. 1146-1151, June 1997.

[7] B. Gao, K. Sanada and K. Furihata, "A Study on Yow Rate Control of Hydralic-Power-Steering Heavy Duty Vehicles," in SICE Annual Conference, pp. 2866-2870, September 2007.

[8] D. Graovcac, B. Köppl, A. Kiep and M. Pürschel, "Optimal PWM Method for Electric and Electro-Hydraulic Power Steering Applications," in IEEE Power Electronics Specialists Conference, June 2008.

[9] S. Rhyu, Y. Kim, J. Choi and J. Hur, "Development of an Electric Driven Pump Unit for Electro-Hydraulic Power Steering of 42 V Automobile," in IEEE Vehicle Power and Propulsion Conference, September 2007.

[10] T. Takagi and M. Sugeno, "Fuzzy Identification of Systems and Its Applications to Modeling and Control," in IEEE Transactions on Systems, Man and Cybernetics, vol. SMC-15, no. 1, pp. 116-132, January/February, 1985.

[11] M. Sugeno, T. Murofushi, T. Mori, T. Tatematsu, J. Tanaka. "Fuzzy algorithmic control of a model car by oral instructions," in Fuzzy Sets and Systems, vol. 32 , issue 2, pp. $207-219,1989$.

[12] J.E. Naranjo, C. Gonzlez, J. Reviejo, R. Garca, T. de Pedro, and M.A Sotelo, "Using Fuzzy Logic in Automated Vehicle Control" in IEEE Intelligent Systems, pp. 36-45, Jan/Feb 2007. 